\title{
Mapeamento de políticas públicas para os refugiados no Brasil
}

\section{Mapping public policies for refugees in Brazil}

\author{
Mapeo de políticas públicas para los refugiados en Brasil
}

\author{
Rômulo Ataides França* \\ Universidade de Brasília - UnB, Brasília, Distrito Federal, Brasil \\ Wilsa Maria Ramos** \\ Universidade de Brasília - UnB, Brasília, Distrito Federal, Brasil
}

Maria I nez Montagner***

Universidade de Brasília - UnB, Brasília, Distrito Federal, Brasil

\begin{abstract}
RESUMO
Frente à chegada de imigrantes refugiados ao Brasil, surge a preocupação acerca do alcance das políticas públicas estabelecidas para o acolhimento dessas pessoas no país. Para tanto, realizou-se a revisão documental e de literatura buscando mapear as legislações e documentos de órgãos oficiais sobre os refugiados, bem como a produção acadêmica sobre os eixos temáticos políticas públicas, saúde e xenofobia, no período entre 2007 a 2017. Não foram encontrados artigos brasileiros sobre refugiados e xenofobia. A falta de políticas públicas ampla foi um aspecto diagnosticado pelas produções relacionadas aos eixos saúde e políticas públicas. O problema das migrações forçadas tende a atingir cada vez mais o Brasil, de forma que este estudo pode contribuir para a sofisticação das estruturas legislativas e sociais para lidar com o acolhimento de refugiados no Brasil.
\end{abstract}

Palavras-chave: refugiados, políticas públicas, vulnerabilidade, saúde.

\begin{abstract}
Faced with the arrival of refugee immigrants to Brazil, there is concern about the scope of the public policies established for the reception of these people in the country. A documentary and literature reviews were carried out to map the legislation and documents of institutional bodies on refugees and the academic production on the thematic axes public policies, health and xenophobia in the period between 2007 and 2017. No results were found for Brazilian articles on refugees and xenophobia, the lack of broad public policies was an aspect diagnosed by the productions related to health and public policies. The problem of forced migration tends to reach Brazil more and more, this study can contribute to the sophistication of the legislative and social structures to deal with the proper reception of refugees in Brazil.

Keywords: refugees, public policies, vulnerability, health.
\end{abstract}




\begin{abstract}
RESUMEN
Frente a la llegada de inmigrantes refugiados a Brasil, surge la preocupación sobre el alcance de las políticas públicas establecidas para la acogida de esas personas en el país. Para ello, se realizó una revisión documental y de literatura buscando mapear las legislaciones y documentos de órganos oficiales sobre los refugiados y la producción académica basada en los ejes temáticos políticas públicas, salud y xenofobia en el período entre 2007 a 2017. No se encontraron artículos brasileños relacionando refugiados y xenofobia, la falta de políticas públicas amplias fue un aspecto diagnosticado por las producciones relacionadas a los ejes salud y políticas públicas. El problema de las migraciones forzadas tiende a atingir cada vez más a Brasil, de forma que este estudio puede contribuir a la sofisticación de las estructuras legislativas y sociales para tratar con la acogida de refugiados en Brasil.
\end{abstract}

Palabras clave: refugiados, políticas públicas, vulnerabilidad, salud.

Em meio ao atual contexto global de fechamento político, no que concerne às políticas migratórias na Europa e, sobretudo nos EUA, a problemática envolvendo a imigração em massa de refugiados vem ganhando cada vez mais o debate público. Soma-se como preocupação os crescentes ataques terroristas na Europa, que têm aumentado a xenofobia, enquanto prática social, inclusive endossada por líderes políticos como argumento em favor da segurança nacional, dificultando a entrada de refugiados em seus países (Amaral, 2016; Garcia, 2011; Pozza, 2016).

O estudo abrangeu a revisão documental e a revisão de literatura que tinham como objetivo mapear as legislações e documentos oficiais sobre políticas públicas para os refugiados, bem como levantar a produção acadêmica sobre o tema entre 2007 e 2017. Pretendeu-se gerar informações que possam influenciar a tomada de decisões no âmbito dos organismos públicos e nos organismos não governamentais, considerando que não parece haver, de modo sistemático, um "campo de públicas" (Farah, 2016) bem estabelecido no Brasil para essa demanda específica e emergente.

\title{
Metodologia
}

O estudo teve financiamento de um Observatório que pretendia identificar a situação de populações vulneráveis no Brasil. Para abranger os interesses da investigação, foram realizadas pesquisas bibliográficas com dois enfoques. O primeiro foi a revisão documental, que se baseou em um levantamento da legislação brasileira, de documentos oficiais e busca de sites que detenham informações sobre os locais de atenção e atendimento nos estados e municípios que recebem maior fluxo migratório. E o segundo foi a revisão de literatura que identificou os artigos sobre o tema 
refugiados no Brasil nos eixos de interesse específico da pesquisa: políticas públicas - saúde - xenofobia. As informações construídas a partir dos estudos poderão auxiliar na constituição de um campo de estudo disciplinar ou multidisciplinar para futuras pesquisas.

$\mathrm{Na}$ leitura preliminar foram encontrados artigos, dissertações de mestrado e teses de doutorado, publicados entre 2007 e 2017, de diferentes áreas que extrapolam os objetivos do estudo, mas que tratam do tema "refugiados". A diversidade das áreas envolvidas nos temas da literatura sobre o fenômeno da migração também deve ser levada em consideração como um aspecto relevante sobre o modo como os estudos abordam as políticas públicas.

Os dados sobre a legislação brasileira e os organismos de assistência aos refugiados foram coletados de Estatutos, Decretos e documentos oficiais de acesso público, fornecidos pelos sites de administração dos estados e dos municípios, documentos do Auto Comissariado das Nações Unidas para Refugiados (ACNUR) e do Comitê Nacional para os Refugiados (CONARE). Em termos de resultado do trabalho, espera-se que o mapeamento dos estudos seja capaz de refletir os seus alcances e os limites, sendo base para acompanhamentos das políticas públicas e das ações de amparo aos imigrantes refugiados no Brasil.

As informações da literatura foram coletadas nas plataformas de banco de dados SciELO e na BDTD vinculadas ao IBICT. Para a busca dos artigos, utilizou-se a plataforma SciELO, e na busca de dissertações e teses dos programas de pós-graduação no Brasil utilizou-se a Plataforma BDTD - IBICT com o descritor "refugiados", combinado com uma das palavras dos eixos de investigação, tais como "xenofobia", "políticas públicas", "saúde", conforme descrito na tabela 1. Os critérios de inclusão e exclusão de estudos foram definidos pela relação com os eixos e temáticas relacionados a refugiados. Foram selecionadas apenas produções em português, usando o filtro "português" nas duas plataformas estudadas, e cujo estudo estivesse situado no contexto nacional. Estudos nacionais que estivessem contextualizados em circunstâncias e fenômenos no exterior foram descartados, e estudos que focassem em períodos e fenômenos históricos passados, muito específicos, também foram descartados. Por esses critérios, a temática da xenofobia não foi contemplada na análise, visto que, em ambas as plataformas SCiELO e BDTD -, as produções (artigos, dissertações e teses) abordavam apenas casos europeus. A seleção das produções consideradas neste estudo foi feita no período de maio a junho de 2017. Publicações posteriores, bem como mudanças no funcionamento e nos algoritmos de busca nas bases de dados citadas não foram consideradas. Desse modo, buscas posteriores podem apontar uma quantidade de produções diferente daquela apresentada aqui. 
Tabela 1

Resultado da Busca Booleana

\begin{tabular}{lcccl}
\hline Palavras & & SciELO & BDTD & \multicolumn{1}{c}{ Seleção dos artigos } \\
\hline $\begin{array}{l}\text { Refugiados } \\
\text { Políticas Públicas }\end{array}$ & 4 & 16 & $\begin{array}{l}\text { Da plataforma SciELO } \\
\text { selecionamos 1 artigo e da } \\
\text { plataforma BDTD 7 produções. }\end{array}$ \\
$\begin{array}{l}\text { Refugiados } \\
\begin{array}{l}\text { Xenofobia } \\
\text { And }\end{array}\end{array}$ & 1 & 1 & $\begin{array}{l}\text { Ambas produções foram } \\
\text { descartadas por não serem } \\
\text { estudos focados em contexto } \\
\text { nacional }\end{array}$ \\
$\begin{array}{l}\text { Refugiados } \\
\text { Saúde }\end{array}$ & AND & 13 & 9 & $\begin{array}{l}\text { Foram selecionados 2 artigos da } \\
\text { plataforma SciELO e 3 } \\
\text { produções da plataforma BDTD }\end{array}$ \\
\hline
\end{tabular}

A partir da busca booleana, usando somente o descritor "refugiados" na Plataforma BDTD, foram encontradas 96 dissertações de mestrado e 33 teses de doutorado. No SciELO, também com o uso do descritor "refugiados", foram encontrados 164 artigos, e cruzando-se "refugiados" e "políticas públicas", quatro artigos. Destes, apenas um foi incluído no estudo. Na plataforma BDTD, combinando-se os descritores "refugiados" e "políticas públicas", foram encontradas 16 produções. Destas, apenas sete foram incluídas no trabalho. Ao combinar o termo "refugiados" com "xenofobia", encontrou-se, nas duas plataformas, apenas uma produção em cada termo. Ambas foram descartadas por não tratarem do problema da xenofobia no contexto nacional. Ao combinar o descritor "refugiados" com o descritor "saúde" foram encontrados 13 artigos na plataforma SciELO e nove produções na Plataforma BDTD. Foram incluídas no estudo três produções da plataforma BDTD e duas produções da plataforma SCiELO.

Foram selecionados seis estados para exemplificar a existência e/ou falta de políticas públicas em níveis estadual e municipal, sendo que três, por serem estados fronteiriços - Acre, Roraima e Amapá estariam suscetíveis a situações de entrada e saída de pessoas do país por via terrestre. A escolha dos estados de São Paulo e Rio Grande do Sul se deu por se tratarem de grandes centros, cujas regiões concentram a população de refugiados no país (Busko, 2017; Conare, 2016). O Distrito Federal foi escolhido por nele estar situado - centro de poder político brasileiro, concentrando um aeroporto internacional, embaixadas e sedes de organizações como a Conare, o Instituto de Migrações e Direitos Humanos e a ACNUR. Os documentos relacionados a esses estados foram selecionados e lidos pelo próprio pesquisador. 


\section{Análise das informações sobre as políticas públicas e programas para refugiados no Brasil}

Em 1997 foi criado na legislação brasileira o Estatuto dos Refugiados, Lei 9.474. Inspirado pela Convenção de Genebra, cria também o Comitê Nacional para os Refugiados (CONARE), órgão multiministerial que trabalha no âmbito do Ministério da Justiça. De acordo com a definição dada no Estatuto do Refugiado (Lei n. 9.474, 1997), o imigrante refugiado tem "fundados temores de perseguição por motivos de raça, religião, nacionalidade, grupo social ou opiniões políticas" e sofre de "grave e generalizada violação de direitos humanos", que o impede de permanecer em seu país de origem (Milesi \& Carlet, 2012; Silva \& Rodrigues, 2012).

Segundo dados do Comitê Nacional para os Refugiados, de 2010 a 2016 foram registrados 9.993 imigrantes no Brasil, e nos anos de 2014 e 2015 houve mais de 28.000 pedidos, sendo que, em 2016, registrou-se mais de 10.308 pedidos de refúgio. Por ser um grande centro urbano e abrigar a capital do país, o Distrito Federal também está no mapa do fluxo de refugiados que chegam a cada ano, recebendo $1 \%$ das solicitações de refúgio em 2017. Considerando a recente crise imigratória originária de guerras civis e/ou conflitos de natureza étnico-religiosa por todo o mundo, o Brasil tende a receber um contingente cada vez maior de refugiados oriundos da Venezuela, Cuba, Haiti, Angola e Síria (Conare, 2016).

Entre os problemas identificados que circunscrevem o cotidiano dos refugiados, estão as questões relacionadas aos cuidados da saúde, educação e trabalho. No caso da saúde, por exemplo, há certo despreparo profissional de funcionários do Sistema Único de Saúde (SUS), seja por diferenças culturais em relação ao cuidado ou mesmo por conta da não compreensão da língua falada, uma vez que muitos refugiados não se comunicam bem em português (Silva, 2013).

Também são comuns os problemas na recolocação dessas pessoas no mercado de trabalho, onde estão à mercê de péssimas condições de trabalho, além de serem vítimas potenciais de trabalho escravo, tráfico de pessoas, racismo, e acabam por viver em moradias em péssimas condições (Araújo, 2015). Apontam-se possibilidades de inclusão social e empoderamento dessa população através das ferramentas digitais, seja por meio de divulgação de informação e jornalismo contra hegemônico (Aragão \& Santi, 2018), seja pelo uso de redes sociais como modo de apropriação de língua e cultura do país receptor (Ayuste et al., 2017).

O trabalho de acolhimento direto e de assistência a esses imigrantes é, em grande parte, realizado por organizações não governamentais, resultado do empenho da sociedade civil (Moreira, 2014; Schwinn \& Freitas, 2015), com apoio do ACNUR. Algumas organizações sociais para assistência aos refugiados são: Projeto Vidas Refugiadas, que é 
voltado para mulheres que pedem refúgio no Brasil; ONG Abraço Cultural, que oferece aulas de idiomas com professores refugiados, fundada em 2014. Também há institutos e centros especiais como o Instituto de Reintegração do Refugiado, fundado em 2010, e o Instituto Migrações, fundado em Brasília em 1999. O IMDH se destaca como umas das instituições mais importantes na acolhida direta a imigrantes refugiados no país, inclusive mediando o contato dos imigrantes com a Polícia Federal e a ACNUR. Além da acolhida, o Instituto também promove eventos e realiza publicações sobre o assunto. Vale destacar também o Centro de Acolhida a Refugiados (Caritas Brasil), que foi fundado em 1956, e a Casa do Imigrante em São Paulo, onde se realização a Missão Paz.

Em 21 de novembro de 2017 entrou em vigor a chamada Lei das Migrações, que substitui o Estatuto do Estrangeiro, de 1980, atualizando e humanizando o acolhimento aos refugiados à luz dos direitos humanos, demonstrando avanços no tratamento aos imigrantes, incluindo apátridas, vítimas de tráfico de pessoas, bem como brasileiros que vivem no exterior. A nova lei dá um tratamento mais humanitário aos estrangeiros, que eram considerados uma ameaça à segurança nacional, bem como também se foca na garantia de direitos, liberdades e marca o repúdio à discriminação e à xenofobia (Oliveira, 2017).

Quanto aos recursos públicos investidos nas políticas e programas para refugiados selecionamos seis estados brasileiros, conforme descrito a seguir.

\section{São Paulo}

O município de São Paulo foi o primeiro a possuir uma política municipal para imigrantes. Sancionada em 2016, a lei 16.478 instaura uma articulação entre a Secretaria Municipal de Direitos Humanos e Cidadania da prefeitura de São Paulo com o acesso de imigrantes aos serviços públicos em igualdade de direitos com os cidadãos nativos, além de fomentar a diversidade e facilitação na aquisição de documentos. Também instaura a formação de agentes para o trabalho continuado com a população imigrante, incluindo a contratação de agentes imigrantes, criando uma estrutura de acolhimento e proteção por meio do poder público. São Paulo também possui os Centros de Referência e Atendimento para Imigrantes (CRAI), mantidos pelo poder público municipal para a inclusão social dos imigrantes, independente de suas circunstâncias e situação documental. Por parte do governo estadual, foi criada, em 2014, a Casa de Passagem Terra Nova, por meio da Secretaria de Desenvolvimento Social do Estado de São Paulo. Localizada na capital do Estado, a casa possui 50 vagas de atendimento, com uma estrutura de 10 quartos, área de convivência, brinquedoteca, 
refeitório e salas de atendimento individualizado. A casa oferece apoio social e jurídico, atividades ocupacionais e culturais, além de aulas de língua portuguesa e encaminhamento para a rede de políticas públicas. Os encaminhamentos para atendimento são realizados pela Cáritas, Missão de Paz, Posto Humanizado de Guarulhos e pela Secretaria de Estado da Justiça e Defesa da Cidadania.

\section{Rio Grande do Sul}

O Rio Grande do Sul possui o decreto no 49.729, de 2012, que instaura o Comitê Gaúcho de Atenção para Migrantes, Refugiados, Apátridas e Vítimas de Tráfico de Pessoas (COMIRAT). Coordenado pela Secretaria da Justiça e dos Direitos Humanos, o comitê visa fortalecer políticas públicas, produzir conhecimentos e planos de ação para esta população.

Ainda no Estado do RS, em Porto Alegre, foi criado o Decreto $\mathrm{N}^{\circ}$ 18.815 de 2014, que institui o Comitê Municipal de Atenção aos Imigrantes, Refugiados, Apátridas e Vítimas do Tráfico de Pessoas, coordenado pela Secretaria de Direitos Humanos da prefeitura de Porto Alegre. Visa a proteção, garantia de direitos e devido acolhimento de imigrantes e o fomento à produção de conhecimento na área. É composto por membros de diversas outras secretarias municipais e instituições, como a Cátedra Sergio Vieira de Mello, PUCRS, UFRGS e Cáritas-RS.

\section{Distrito Federal, DF}

O DF não possui política pública específica para refugiados, sendo o acolhimento realizado pelo aparelho público de assistência social que já existe na região, como a rede dos Centros de Referência de Assistência Social (CRAS) e a Central de Vagas de Acolhimento e Atendimento Emergencial (UNISUAS), pelas embaixadas e pela Polícia Federal, bem como por organizações não governamentais, como o "Um mundo com mais pontes e menos muros" e a Cátedra Sergio Vieira de Mello, vinculada ao Departamento de Letras da Universidade de Brasília, que promove projetos de ensino de português para estrangeiros e iniciativas de inclusão de imigrantes refugiados e em vulnerabilidade social na vida acadêmica ${ }^{1}$. No entanto, em 2017 foi elaborado o Plano Decenal Distrital dos Direitos de Crianças e Adolescentes (2017 - 2027) que, além do DF, deverá também ser adaptado para as outras unidades da federação. 


\section{Estados fronteiriços: Acre, Roraima e Amapá}

Os Estados fronteiriços listados não possuem política pública específica para atender a refugiados. Atualmente, o Estado de Rondônia enfrenta uma crise envolvendo a entrada de imigrantes venezuelanos, país que faz fronteira com o estado. Devido à crise política que assola a Venezuela, muitos imigrantes têm chegado à região, resultando em uma crise humanitária no Estado, que não tem preparo ou estrutura para receber os mais de 40.000 venezuelanos que entraram em território brasileiro (Mendonça, 2018). Essa situação tem gerado movimentos distintos por parte da mídia tradicional, que tende a ser agressiva e inquisidora em relação aos imigrantes, e das redes sociais digitais que, com o apoio de estudantes do Estado, tentam uma aproximação mais empática ao problema (Aragão \& Santi, 2018).

As políticas públicas estaduais são frequentemente marcadas pela urgência de ações, onde órgãos não governamentais e secretarias vinculadas às prefeituras (em geral dos grandes centros) unem esforços a fim de resolver situações sérias envolvendo os refugiados, quando o aparelho público se mostra ineficiente para atender as demandas que lhe são apresentadas.

Entre os estados selecionados, São Paulo apresenta a melhor estrutura para receber e acolher imigrantes refugiados. Considerando que é o Estado que concentra a maior riqueza do país, também concentra o interesse da maior parte dos refugiados que vão em busca de empregos e melhores condições de vida. Inclusive, em 2016, foi sancionada a Lei Municipal no 16.478, Lei do Migrante, que é mais um pilar para o fortalecimento estrutural de outros serviços já disponíveis (Cáritas, SESC, SENAI, CRAI e outros). No entanto, tal reforço "estrutural", legal e político por parte das secretarias municipal e estadual revela, mais uma vez, a crítica de que as circunstâncias emergenciais pautam as ações governamentais (Lussi, 2015; Perin, 2013; Silva, 2013).

Compreende-se que o mesmo possa ser dito do Rio Grande do Sul, que possui uma estrutura legislativa similar à encontrada em São Paulo e também concentra um grande contingente dos refugiados no Brasil, bem como muitos estudos sobre essa população, possivelmente fomentados pela presença de membros da UFRGS, PUC-RS e Cátedra Sergio Vieira de Mello nos comitês estaduais e municipais dedicados aos refugiados. Inclusive, nesse estado, as propostas de ação contemplam políticas públicas voltadas para a inserção social dos refugiados, via educação (Busko, 2017).

O caso do Distrito Federal e dos Estados fronteiriços abordados é menos sofisticado, uma vez que não há, nessas regiões, políticas públicas específicas. No DF, há grande ação de instituições como o Instituto Migrações. Na região Norte, nos três estados selecionados 
( $R R$, RO e AP), não se encontraram iniciativas consistentes por parte dos governos para o acolhimento de refugiados. Espera-se que a entrada em vigência da nova Lei das Migrações force mais ações em nível federal, para que a devida formulação de políticas públicas mais sofisticadas e abrangentes ocorra para essa população.

\section{Análises das produções acadêmicas com concentração nos eixos temáticos: xenofobia, políticas públicas e saúde dos refugiados no Brasil}

Conforme descrito na seção de metodologia, na Tabela 1 , foram selecionados 13 artigos das produções acadêmicas no período 2007 a 2017. A organização foi realizada por tema para mapeamento das áreas de interesse da pesquisa sobre os eixos refugiados e políticas públicas e refugiados e saúde.

\section{Refugiados e Políticas Públicas}

Os artigos e produções selecionados abordam as relações entre o funcionamento e o não-funcionamento/existência de políticas públicas com as relações entre os refugiados e as instituições nacionais.

Tabela 2

Politicas Públicas e Refugiados

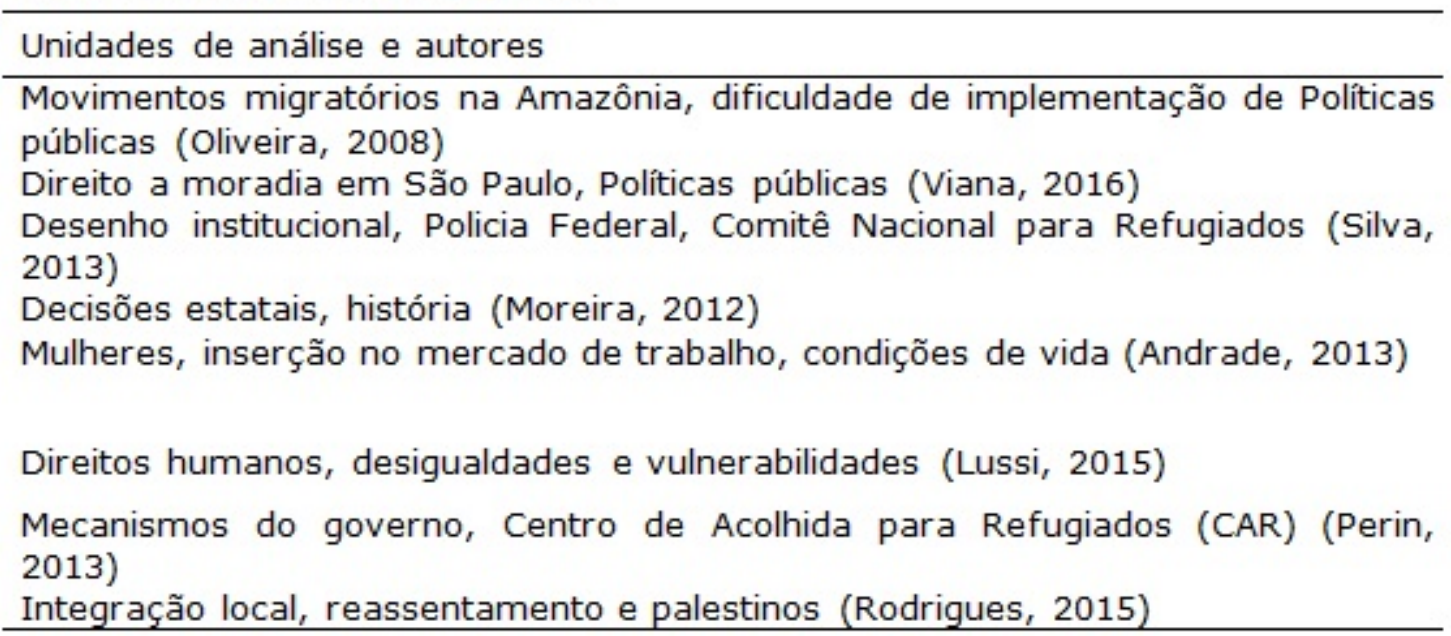

No tema de Políticas Públicas nas produções analisadas encontramos oito produções que abordam o tema de modo central ou transversal. Algumas não trazem uma conceitualização sobre "políticas públicas". Lussi (2015) destaca que a Política Migratória Brasileira precisa aprender a responder aos maiores fluxos de migrantes, bem como manejar sua própria organização política para receber esse contingente. Realça também que a presença desses migrantes pode 
revelar deficiências políticas claras, como a transgressão das leis trabalhistas, que oportunizam condições de trabalho escravo, e a vulnerabilidade a que estão expostos os mais pobres no país.

Perin (2013) reforça a descentralização das políticas públicas de acolhimento a refugiados, mencionando três aparatos: ACNUR, Polícia Federal/CONARE e a Sociedade Civil, focando seu estudo no Centro de Acolhida, em São Paulo, do qual expõe as dificuldades burocráticas e insuficiências dos serviços existentes através de uma etnografia. Problemas também são apontados por Oliveira (2008), cujo trabalho analisa entrevistas com refugiados colombianos no Amazonas, revelando a desconfiança em relação às instituições que deveriam acolhê-los - ACNUR, CONARE e Polícia Federal - e os maus tratos e insensibilidade de seus funcionários.

Viana (2016) expõe as dificuldades dos refugiados em conseguir moradia em São Paulo, motivo pelo qual muitos se estabelecem em ocupações de prédios abandonados no centro da cidade, uma vez que - custo de vida na cidade é alto e as casas de acolhida são insuficientes para a demanda de pessoas que aí chegam. A não capilaridade das políticas públicas para essa população no Brasil é criticada por Silva (2013), que afirma que a CONARE se preocupa em estabelecer critérios de elegibilidade e reconhecimento de refugiados, delegando sua integração à sociedade civil organizada, o que revela um descompasso entre poder público e a própria sociedade civil.

Moreira (2012) reforça a crítica anterior e faz uma reconstituição histórica da construção das políticas de refúgio no Brasil. Seu estudo mostra que tal situação vem crescendo desde o final dos anos 70, indicando a atividade e envolvimento ativo dos próprios refugiados na concepção das políticas públicas (aspecto contemplado na atual Lei Municipal no 16.478 de São Paulo). Em um recorte de gênero, Andrade (2013) expõe a falta de políticas públicas específicas para mulheres refugiadas que, muitas vezes, ficam impossibilitadas de trabalhar por conta dos filhos muito novos, e tampouco conseguem creches, tendo que contar com poucas instituições de caridade para conseguirem se manter no trabalho.

Há produções que tratam de populações reassentadas, cujos beneficiados passam por um trâmite diferenciado de entrada no Brasil. No entanto, poucas produções tratam especialmente da problemática da política pública. Rodrigues (2015) indica que os programas de reassentamento se concentraram nos Estados do RS, interior do RJ, interior de SP, e RN, tendo um número reduzido de refugiados contemplados, que entravam em grupos de 30 pessoas e passavam por um processo de seleção. De modo geral, as produções apresentam as políticas públicas sempre no viés de sua falta ou sua insuficiência, mostrando que as ações do governo parecem ser pautadas sempre pelo caráter da emergência. 


\section{Refugiados e Saúde}

As produções relacionadas à saúde dos refugiados abordam os temas saúde mental e física, prevenção e atendimento médico (Tabela 3).

Tabela 3

Saúde dos Refugiados

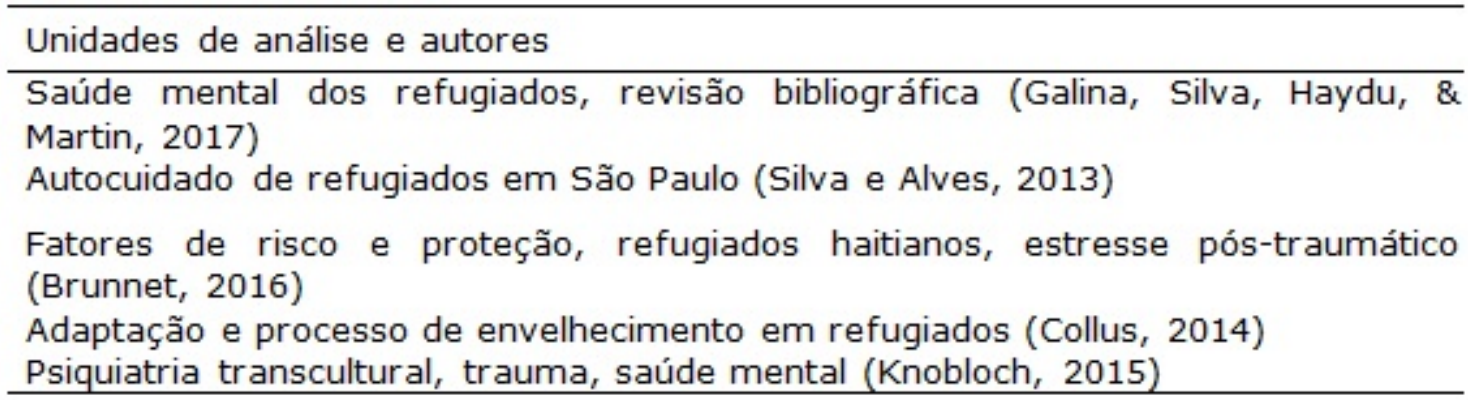

Os estudos demonstram a ausência de políticas públicas abrangentes e estruturadas para a área de saúde. Collus (2014) investigou os aspectos sociais e culturais de refugiados com mais de 55 anos na cidade de São Paulo, e aponta para o despreparo do Estado para o acolhimento e suporte dos refugiados. Na condição de pesquisadora e funcionária de uma unidade do SESC, apresenta em detalhes o funcionamento dos serviços oferecidos pelo Serviço Social de Comércio de São Paulo em parceria com a Caritas.

Silva e Alves (2013) apresentam o funcionamento desses serviços ao acolhimento de demandas sanitárias dos refugiados, em especial por saúde bucal, sua área de formação, destacando as práticas de autocuidado dos refugiados como uma alternativa de promoção de saúde para essa população, bem como seus atritos com as práticas médicas padrão no Brasil. Brunnet (2012) estuda os fatores associados com o Transtorno de Estresse Pós-traumático em refugiados haitianos no RS, desde uma perspectiva clínica, mas não trata de políticas públicas ou saúde pública de modo amplo. As outras produções da categoria "Saúde dos refugiados" não trazem novidades ou abordagens significativas para o direcionamento de políticas públicas para refugiados no Brasil.

Por outro lado, Knobloch (2015) apresenta uma crítica ao que chama de "patologização" da experiência de migração como forma de inserir o refugiado e colocá-lo legalmente em visibilidade, porém não o considerando enquanto indivíduo com subjetividade e autonomia. $\mathrm{O}$ diagnóstico de Transtorno de Estresse Pós-traumático é colocado como uma ferramenta política que contribuiu para a medicalização do fenômeno migratório como forma de aculturá-lo e inseri-lo no sistema brasileiro. 
Galina et al. (2017) apresentam uma revisão bibliográfica de artigos internacionais sobre a saúde mental de refugiados, onde se destaca a importância das redes de apoio social e da organização dos sistemas de saúde dos países acolhedores como fatores que diminuem o sofrimento psíquico dos refugiados. Quanto à saúde mental de jovens e crianças, ressalta-se o nível de organização das famílias e o amparo educacional e acadêmico como fatores que promovem saúde mental. Os autores também destacam a importância do preparo dos profissionais de saúde em lidar com a interculturalidade. Vale ressaltar que o cruzamento dos termos refugiados e xenofobia não apresentou nenhum resultado de publicação.

Os estudos encontrados nos eixos temáticos refugiados e políticas públicas, e refugiados e saúde apontam as falhas e ineficiências quanto à inexistência de ações no que concerne às políticas públicas, que são distribuídas na federação brasileira em forma de iniciativas estatais e sempre com a participação da sociedade civil, mas sem ações organizadas e padronizadas em nível nacional.

No eixo refugiados e saúde destaca-se, além da ineficiência dos serviços públicos, o não preparo adequado dos profissionais de saúde para lidar com as delicadas circunstâncias de atendimento a essa população. Esses dados revelam que quando não existe um modelo de assistência aos refugiados no Brasil, ações pontuais são tomadas. Entretanto, com o crescente ciclo migratório internacional, devido às guerras civis ou graves incidentes naturais, há necessidade de políticas, programas e ações programáticas para recebimento e acolhimento dessa população.

Outro resultado preocupante refere-se ao fato de não terem surgido produções, no recorte do levantamento feito, que trabalhem a xenofobia no contexto nacional. Esse dado aponta para uma falta de interesse da academia sobre o tema no Brasil que, ao invés de estudar o fenômeno do preconceito contra os imigrantes, investiga os fatores de prevenção à xenofobia. Para tanto, recomenda-se a produção de estudos focados nas nuances da xenofobia, tendo em vista a diversidade sociocultural e étnica do país.

\section{Considerações Finais}

A análise das informações bibliográficas e documentais evidencia a falta de uma área de estudos que discutam de forma aprofundada as políticas públicas para refugiados no Brasil. As produções encontradas, sobretudo os estudos realizados nos mestrados e doutorados nos programas de pós-graduação brasileiros, são numerosas e plurais, e abrangem várias áreas do conhecimento e diversos objetos de estudo. No entanto, apontam sua própria insuficiência para propor ações efetivas em nível do planejamento de 
políticas públicas. Farah (2016) argumenta em favor da definição de "campo das ações públicas" dedicado ao pensamento, estudo e estruturação de políticas públicas específicas, e no presente estudo identificamos a mesma necessidade para os refugiados no Brasil, possibilitando, no futuro, lograr o estabelecimento de um campo de estudo que permita o desenvolvimento efetivo da área. Por último, vale considerar que a aprovação da nova Lei das Migrações em 2017 pode ser um passo importante e oportuno para a melhoria do sistema de refúgio brasileiro, desde que o governo trate com seriedade esse fenômeno que marca a história da humanidade. O problema global do deslocamento forçado de pessoas começa a atingir o Brasil de forma crescente, e uma pesquisa de revisão documental da legislação correspondente e de literatura acadêmica sobre o tema no Brasil, ainda que com as limitações de quantidade encontrada, pode apontar para aspectos a serem avançados a nível de estudo, ampliando os eixos temáticos e sobretudo discutindo as necessidades de ampliação e criação de políticas públicas urgentes que atendam a agenda social de acolhimento do refugiado e as demandas por fomento e financiamento de ações estratégicas que ainda haverão de ser enfrentadas pelos estados e municípios que estão no fluxo migratório.

\section{Referências}

Abraço Cultural. (n.d.). Sobre o Abraço. Recuperado de http://abracocultural.com.br/sobre-o-abraco/

Amaral, R. A. D. (2016). Violência Cultural: Xenofobia, Terrorismo e o Advento da Intolerância nas relações transnacionais. Anais da Semana de Relações Internacionais - O Sul Global: De Bandung ao Século XXI, São Bernardo do Campo, SP, Brasil, 1.

Andrade, M. (2013). Mulheres refugiadas e o mercado de trabalho: Um estudo no município de São Paulo (Dissertação de Mestrado). Pontifícia Universidade Católica de São Paulo, São Paulo, SP, Brasil. Recuperado de https: //tede2. pucsp. br/bitstream/handle/17667/1/Marisa\% 20A ndrade.pdf

Aragão, T., \& Santi, V. (2018). Somos migrantes: o uso das redes sociais na produção midiática alternativa sobre a migração venezuelana em Roraima. Aturá: Revista Pan-Amazônica de Comunicação, 2(1), 136-156. Recuperado de https://sistemas. uft.edu.br/periodicos/index. php/atura/article/v iew/ 4627

Araújo, A. A. A. (2015). Reve de Brezil: A inserção de um grupo de imigrantes haitianos em Santo André.São Paulo - Brasil (Dissertação de Mestrado). Universidade Federal do ABC, Santo André, SP, Brasil. Recuperado de 
http: //diversitas.fflch.usp.br/sites/diversitas.fflch.usp.br/files/Di sserta\% C3\% A7\% C3\% A30\% 20Adriano\% 20Ara\% C3\% BAjo.pdf

Ayuste, A., Escofet, A., González, O., Begoña, G., Llobet-Estany, M., Montserrat, P., Sancho, J., \& Zhang-Yu, C. (2017). Apps4me: Empoderamiento de ciudadanos inmigrantes mediante el diseño participativo de plataformas sociales digitales. Barcelona: Universitat de Barcelona.

Brunnet. A. E. (2016). Prevalência e fatores associados a sintomas de estresse pós-traumático, depressão e ansiedade em imigrantes haitianos no Rio Grande do Sul (Dissertação de Mestrado). Pontifícia Universidade Católica do Rio Grande do Sul, Porto Alegre, Brasil. Recuperado de http://tede2. pucrs.br/tede2/handle/tede/ 6944

Busko, D. (2017). Políticas públicas educacionais para imigrantes e refugiados no Rio Grande do Sul. Jornal de Políticas Educacionais, 11(22), 1-20. Recuperado de https://revistas. ufpr.br/jpe/article/view/55131/34478

Campos, M. (2015). Ensaio sobre a construção de informações sobre migração internacional no Brasil. Refúgio, Migrações e Cidadania, Caderno de Debates, 10(10), 35-54. Recuperado de https: //www.acnur.org/portugues/wpcontent/uploads/2018/02/Caderno-de-Debates-

10_Ref\% C3\% BAgio-Migra\% C3\% A7\% C3\% B5es-e-Cidadania.pdf

Cáritas Brasileira. (2013). Quem somos e histórico. Brasília: Cáritas brasileira. Recuperado de http://caritas.org.br/quem-somos-ehistorico

Collus, D. O. (2014). Envelhecer longe de casa: Aspectos culturais e sociais de refugiados na cidade de São Paulo (Dissertação de Mestrado). Pontifícia Universidade Católica de São Paulo, São Paulo, SP. Recuperado de https: //sapientia.pucsp.br/bitstream/handle/12459/1/Denise\% 200rlandi\% 20Collus.pdf

Conare. Secretaria Nacional de Justiça. (2018). Refúgio em números (3a ed.). Brasília, DF: Ministério da Justiça. Recuperado de https://www.acnur.org/portugues/wpcontent/uploads/2018/04/refugio-em-numeros 1104.pdf

Decreto no 18.815, de 10 de outubro de 2014. (2014). Institui o Comitê Municipal de Atenção aos Imigrantes, Refugiados, Apátridas e Vítimas do tráfico de pessoas no município de Porto Alegre e revoga o decreto № 13.717, de 8 de maio de 2002 . Recuperado de https://leismunicipais.com.br/a/rs/p/portoalegre/decreto/2014/1881/18815/decreto-n-18815-2014institui-o-comite-municipal-de-atencao-aos-imigrantesrefugiados-apatridas-e-vitimas-do-trafico-de-pessoas-nomunicipio-de-porto-alegre-e-revoga-o-decreto-n-13717-de-8de-maio-de-2002 
Farah, M. F. S. (2016). Análise de políticas públicas no Brasil: de uma prática não nomeada à institucionalização do "campo de públicas". Revista de Administração Pública, 50(6), 959-979. doi: 10.1590/0034-7612150981

Galina F. V., Silva. T. B. B., Haydu. M., \& Martin. D. (2017). A saúde mental dos refugiados: um olhar sobre estudos qualitativos. Interface - Comunicação, Saúde, Educação, 21(61), 297-308. doi: 10.1590/1807-57622016.0929

Garcia, F. F. (2011). Sobre os Centros de Permanência Temporária na Itália e a construção social da não-pessoa (Dissertação de Mestrado).Universidade Estadual de Campinas, Campinas, SP, Brasil. Recuperado de http://repositorio. unicamp.br/bitstream/REPOSI P/279005/1/Ga rcia_FernandaDiFlora_M.pdf

Governo do Estado de São Paulo. (2017, Junho 20). Casa de Passagem Terra Nova orienta refugiados na busca por emprego. Portal do Governo: SP Notícias. Recuperado de http://www.saopaulo.sp.gov.br/spnoticias/oportunidades-emsp-refugiados-da-casa-de-passagem-terra-nova-conseguememprego/

Instituto Migrações. (2017). O Plano Decenal dos Direitos de Crianças e Adolescentes é importante passo para imigrantes e refugiados no DF. Recuperado de http://www.migrante.org.br/index.php/migrantes2/397-planodecenal-dos-direitos-de-criancas-e-adolescentes-e-importantepasso-para-imigrantes-e-refugiados-no- $\mathrm{df}$

Instituto Migrações. Quem somos. Recuperado de http: //www. migrante.org.br/index. php/2014-01-14-00-3649/quem-somos

Knobloch, F. (2015). Impasses no atendimento e assistência do migrante e refugiados na saúde e saúde mental. Psicologia USP, 26(2), 169-174. doi: 10.1590/0103-6564D20140015

Lei n. 9.474, de 22 de julho de 1997. (1997). Define mecanismos para a implementação do Estatuto dos Refugiados de 1951, e determina outras providências. Presidência da República, Brasil: Subchefia para Assuntos Civis. Recuperado de http://www. planalto.gov.br/ccivil_03/leis/l9474.htm

Lei n. 16.478, de 8 de julho de 2016. (2016). Institui a Política Municipal para a População Imigrante, dispõe sobre seus objetivos, princípios, diretrizes e ações prioritárias, bem como sobre o Conselho Municipal de Imigrantes. São Paulo, SP: Câmara Municipal de São Paulo. Recuperado de https://oig.cepal.org/sites/default/files/2016_ley16.478_bra.pdf

Lussi, C. (2015). Políticas públicas e desigualdad̄es na migração e refúgio. Psicologia USP, 26(2), 136-144. doi:10.1590/01036564D20140014 
Mendonça, H. (2018, Fevereiro 18). Com 40.000 venezuelanos em Roraima, Brasil acorda para sua 'crise de refugiados'. El País Brasil. Recuperado de: https: // brasil.elpais.com/brasil/2018/02/16/politica/151873607 1 492585.html

Milesi, $\bar{R}$., \& Carlet, F. (2012). Refugiados e Políticas Públicas. In C. A. S. Silva (Org.), Direitos Humanos e Refugiados (pp. 77-97). Dourados: Editora UFGD.

Moreira, J. B. (2012). Política em relação aos refugiados no Brasil (1947-2010) (Tese de Doutorado). Universidade Estadual de Campinas, Campinas, SP, Brasil. Recuperado de http://repositorio.unicamp.br/bitstream/REPOSIP/280962/1/Mo reira_J uliaBertino_D.pdf

Moreira, J. B. (2014). Refugiados no Brasil: Reflexões acerca do processo de integração local. REMHU - Revista Interdisciplinar de mobilidade humana, 12(43), 85-98. Recuperado de http://www.scielo.br/pdf/remhu/v22n43/v22n43a06. pdf

Oliveira, A. T. R. (2017). Nova Lei brasileira de migração: Avanços, desafios e ameaças. Ponto de Vista - Revista Brasileira de Estado e Populações, 34(1), 171-179. Recuperado de 10.20947/s0102-3098a0010

Oliveira, M. M. (2008). Refugiados e desplazados na Amazônia: Contribuições para a sociologia dos deslocamentos compulsórios (Dissertação de Mestrado). Universidade Federal do Amazonas, Manaus, Amazonas, Brasil. Recuperado de https: //tede.ufam.edu.br/bitstream/tede/2343/1/Disserta\% C3 $\%$ A7\% C3\% A3०\% 20 -

\% 20M\% C3\% A1rcia\% 20Maria\% 20de\% 200liveira.pdf

Perin, V. P. (2013). “Um campo de refugiados sem cercas”: etnografia de um aparato de governo de populações refugiadas (Dissertação de Mestrado). Universidade Federal de São Carlos. São Carlos, SP, Brasil. Recuperado de http://web.fflch.usp.br/centrodametropole/upload/aaa/861mestrado_Perin_Vanesa_5248.pdf

Pozza, N. F. D. (2016, maio). O racismo e a xenofobia no fenômeno migratório analisados pela égide do pensamento colonial e a (in)atividade do poder público frente a essas práticas. Trabalho apresentado no Seminário Nacional de Demandas Sociais e Políticas Publicas na Sociedade Contemporânea, Universidade de Santa Cruz do Sul, Santa Cruz do Sul, Rio Grande do Sul, Brasil, 12.

Rodrigues, V. M. (2015). Reassentamento e integração local: As limitações institucionais e de políticas em relação aos refugiados palestinos em São Paulo(Tese de Doutorado). Pontifícia Universidade Católica de São Paulo, São Paulo, SP, Brasil. 
https://tede2. pucsp. br/bitstream/handle/3638/1/Viviane\% 20M ozine\% 20Rodrigue.pdf

Schwinn, S. A., \& Freitas, P. (2015). A proteção sociojurídica aos refugiados no Brasil: da legislação à política pública. Barbarói, Santa Cruz do Sul, ed. esp.(44), 255-274. doi: 10.17058/barbaroi.v0i0.7447

Sefras. (2017). Centro de Referência e atendimento para Imigrantes. Recuperado de http://www.sefras.org.br/novo/servicos/sao-paulo/crai/

Silva e Alves, J. (2013). Sorrisos em trânsito: modos de levar a vida e praticar cuidados com o corpo e com a saúde de refugiados exilados no município de São Paulo (Dissertação de Mestrado). Universidade de São Paulo, São Paulo, SP, Brasil. Recuperado de http://www.teses.usp.br/teses/disponiveis/6/6135/tde20082014-144129/pt-br.php

Silva, C. A. S. (2013). A política brasileira para refugiados (1998 2012) (Tese de Doutorado). Universidade Federal do Rio Grande do Sul, Porto Alegre, RS, Brasil. Recuperado de https: //lume.ufrgs.br/bitstream/handle/10183/88351/0009125 44. pdf? sequence $=1$ \&isAllowed $=y$

Silva, C. A. S., \& Rodrigues, V. M. (2012). Refugiados: os regimes internacionais de direitos humanos e a situação brasileira. In C. A. S. Silva (Org.), Direitos Humanos e Refugiados (pp. 123143). Dourados: Editora UFGD.

Viana, L. R. (2016). O Direito de morar no refúgio - a problemática da moradia do refugiado na cidade de São Paulo: saídas individuais ou coletivas? (Dissertação de Mestrado). Pontifícia Universidade Católica do Rio. Rio de Janeiro, RJ, Brasil. Recuperado de https://www.maxwell.vrac. pucrio.br/28263/28263. PDF

Vidas Refugiadas. (n.d.). $O$ Projeto. Recuperado de http://vidasrefugiadas.com. br/o-projeto/

\section{Endereço para correspondência \\ Rômulo Ataides França}

Universidade de Brasília

Instituto de Psicologia, Departamento de Psicologia Escolar e Desenvolvimento Campus Universitário Darcy Ribeiro - ICC Sul, CEP 70910-900, Brasília - DF, Brasil Endereço eletrônico: romuloataides@bol.com.br

\section{Wilsa Maria Ramos}

Universidade de Brasília

Instituto de Psicologia, Departamento de Psicologia Escolar e Desenvolvimento

Campus Universitário Darcy Ribeiro - ICC Sul, CEP 70910-900, Brasília - DF, Brasil

Endereço eletrônico: ramos.wilsa@gmail.com 


\section{Maria I nez Montagner}

Universidade de Brasília

Campus Ceilândia, Quadra QNN 14 - Ceilândia Sul, CEP 72220-140, Brasília - DF, Brasil

Endereço eletrônico: inezmontagner@hotmail.com

Recebido em: 29/10/2018

Reformulado em: 19/03/2019

Aceito em: 20/03/2019

\section{Notas}

* Mestrando em Psicologia na Universidade de Brasília no programa de PósGraduação em Psicologia do Desenvolvimento e Saúde - PG-PDS. Membro do grupo GPPCult. Graduado em Psicologia pela Universidade de Brasília. Pesquisa produção de significados e narrativas de imigrantes forçados e refugiados no Distrito Federal desde perspectivas da Psicologia Cultural.

** Pós-doutorado em Psicologia realizado na Universitat de Barcelona, grupo GRINTIE. Doutorado em Psicologia pela Universidade de Brasília (2005). Mestrado na área de Qualidade de vida no Trabalho na UFMG. Professora da Universidade de Brasília, leciona na graduação no Instituto de Psicologia e orienta no Programa de Pós-graduação em Psicologia do Desenvolvimento e Saúde - PG-PDS. Gestora e pesquisadora de projetos e programas de educação a distância. Tem publicações na área de EaD, educação online, evasão e persistência, cursos MOOC etc tem estudado populações em situação de vulnerabilidade, jovens do sistema socioeducacional e a população em situação de rua. Atualmente, coordena a equipe de produção pedagógica da Escola do Trabalhador.

*** Possui graduação em Ciências Sociais pela Pontifícia Universidade Católica de Campinas (PUCCAMP) (1990), é Mestre (2007) e Doutora (2011) em Saúde Coletiva pelo Departamento de Medicina Preventiva e Social da Faculdade de Ciências Médicas (FCM) da Universidade Estadual de Campinas (Unicamp). Professora Adjunta da Universidade de Brasília (UnB), Campus Ceilândia. Atua como cientista social na saúde coletiva, principalmente com os seguintes temas: gênero, raça/etnia e doenças crônicas (câncer de mama e doença falciforme). Orientadora do Programa de Pós-graduação em Saúde Coletiva da Faculdade de Ciências da Saúde (FS) da UnB, atualmente é Coordenadora do Observatório de Saúde de Populações em Vulnerabilidade - ObVul.

1 Outros projetos voluntários estão descritos no site http:// www. ebc. com. br/cidadania/2015/06/projeto-ajuda-refugiados-no-distritofederal.

Financiamento: Centro de Desenvolvimento Tecnológico da Universidade de Brasília

Este artigo de revista Estudos e Pesquisas em Psicologia é licenciado sob uma Licença Creative Commons Atribuição-Não Comercial 3.0 Não Adaptada. 